\title{
Prediction of Short-Distance Aerial Movement of Phakopsora pachyrhizi Urediniospores Using Machine Learning
}

\author{
L. Wen, C. R. Bowen, and G. L. Hartman ${ }^{\dagger}$
}

All authors: Department of Crop Sciences, University of Illinois, Urbana 61801; and second and third authors: United States Department of Agriculture-Agricultural Research Service, University of Illinois, Urbana 61801. Accepted for publication 8 June 2017.

\begin{abstract}
Dispersal of urediniospores by wind is the primary means of spread for Phakopsora pachyrhizi, the cause of soybean rust. Our research focused on the short-distance movement of urediniospores from within the soybean canopy and up to $61 \mathrm{~m}$ from field-grown rust-infected soybean plants. Environmental variables were used to develop and compare models including the least absolute shrinkage and selection operator regression, zero-inflated Poisson/regular Poisson regression, random forest, and neural network to describe deposition of urediniospores collected in passive and active traps. All four models identified distance of trap from source, humidity, temperature, wind direction,

and wind speed as the five most important variables influencing shortdistance movement of urediniospores. The random forest model provided the best predictions, explaining 76.1 and $86.8 \%$ of the total variation in the passive- and active-trap datasets, respectively. The prediction accuracy based on the correlation coefficient $(r)$ between predicted values and the true values were $0.83(P<0.0001)$ and $0.94(P<0.0001)$ for the passive and active trap datasets, respectively. Overall, multiple machine learning techniques identified the most important variables to make the most accurate predictions of movement of P. pachyrhizi urediniospores short-distance.
\end{abstract}

Phakopsora pachyrhizi Syd. is the fungal pathogen that causes rust on soybean (Glycine max (L.) Merr.) and many other legume hosts (Hartman et al. 2015). Like many other fungi that cause plant rusts, $P$. pachyrhizi produces copious amounts of urediniospore that are readily wind-blown. Since the transoceanic spread of soybean rust from Asia to Hawaii, Africa, South America, and North America during the past two decades (Hartman et al. 2015), various models have been developed to predict $P$. pachyrhizi urediniospores dispersal from one location to another. In November 2004, soybean rust was reported for the first time in the continental United States in the state of Louisiana (Schneider et al. 2005). Based on long-distance transport models, P. pachyrhizi urediniospores may have been moved to the continental United States on winds associated with Hurricane Ivan (Isard et al. 2005), which occurred about 2 months before the discovery of soybean rust in Louisiana.

The discovery of soybean rust in the continental United States brought about much research activity due to the potential of the pathogen to devastate soybean production (Kelly et al. 2015). Yield losses of up to $80 \%$ were reported in experimental plots in Taiwan (Hartman et al. 1991), 30 to 75\% in Brazil (Yorinori et al. 2005), and up to 31,40 , and $27 \%$ in Paraguay, South Africa, and Zimbabwe, respectively (Miles et al. 2007). A network of sentinel plots was established to monitor the occurrences of the disease in the United States and information on its distribution was made available via the Pest Information Platform for Extension and Education (ipmPIPE)

${ }^{\dagger}$ Corresponding author: G. L. Hartman; E-mail: ghartman@illinois.edu

Trade and manufacturers' names are necessary to report factually on available data; however, the USDA neither guarantees nor warrants the standard of the product, and the use of the name by the USDA implies no approval of the product to the exclusion of others that may also be suitable.

*The $\boldsymbol{e}$-Xtra logo stands for "electronic extra" and indicates that five supplementary figures and two supplementary tables are published online.

This article is in the public domain and not copyrightable. It may be freely reprinted with customary crediting of the source. The American Phytopathological Society, 2017.
(Isard et al. 2006b). In the continental United States, $P$. pachyrhizi only survives winters on kudzu and overwintering volunteer soybeans below the frost line (Kelly et al. 2015; Sikora et al. 2014; Yang 2006), and perhaps throughout the Caribbean, causing a bottleneck and often slowing development of rust in the South each spring (Mundt et al. 2013). Data collected through the sentinel plot network shows that rust occurred throughout the southern United States every year since 2004, but spread to northern soybean-growing regions has been less common and, when it occurs, it develops late in the season (USDA 2017). Most commonly, soybean rust has spread locally (within and among adjacent soybean fields), at a rate of 8.8 and $10.4 \mathrm{~km}$ per day in soybean in 2005 and 2006, respectively (Christiano and Scherm 2007).

The dispersal of $P$. pachyrhizi urediniospores is an essential component of the spread of the pathogen, and occurs at all scales ranging from within the plant canopy to across hemispheres. The transport of urediniospores on different regional scales is important for disease modeling and forecasting. There is potential for P. pachyrhizi urediniospores to be launched upward into the atmosphere for longdistance transport through rapidly moving air masses, similar to what may have occurred with Hurricane Ivan (Isard et al. 2005). Anticipating the spread of $P$. pachyrhizi urediniospores in the United States, simulation-based mathematical models were developed to assess the long-distance movement of $P$. pachyrhizi urediniospores from the southern to the northern United States (Isard et al. 2005, 2007, 2011; Krupa et al. 2006; Pan et al. 2006). One model used a climate-dispersion integrated model system to simulate long-distance and long-term movement of $P$. pachyrhizi urediniospores 1 month in advance of an epidemic (Pan et al. 2006). This aerobiological model is based on the Hybrid Single-Particle Lagrangian Integrated Trajectory (HYSPLIT) model which simulates single trajectories of air parcels and deposition of particles originating from a source geographical location and time of year (NOAA 2006). Another model is the Soybean Rust Aerobiology Prediction System (SRAPS) (Isard et al. 2005), which simulates basic spore dispersal processes stated by Aylor (1999). These processes include spore production, release or removal from a substrate, escape from the canopy, transport and dilution by wind, loss of viability during transport, removal from the atmosphere by precipitation, deposition on 
host tissue, and impact in a destination area (Isard and Gage 2001). Previous models that predict the long-distance movement of soybean rust were configured in a modular format to include all stages in the aerobiology process. For example, the SRAPS (Isard et al. 2005) includes the modules of spore release and canopy escape in source areas, mortality due to exposure to solar radiation during atmospheric transport, and wet deposition in destination regions using the National Center for Environmental Prediction-Department of Energy Reanalysis 2 data set (Kalnay 1996; Kanamitsu et al. 2002).

Environmental variables influence $P$. pachyrhizi urediniospores transport models, and more information is needed about what factors influence the release and escape of rust urediniospores from the canopy to the atmosphere (Isard et al. 2005). The release and movement of $P$. pachyrhizi urediniospores from the canopy is influenced by wind and turbulence, the canopy structure, and location of the released spores within the canopy. Precipitation may also play a role in facilitating dislodgement of rust urediniospores from the uredinia (Del Ponte et al. 2006b). After escaping the soybean canopy, turbulent diffusion and wind shear dilute the spores that are transported by airflows, and weather variables such as solar radiation, temperature, and relative humidity affect the survival of spores and dry deposition by wind and turbulence (Gregory 1973) and wet deposition by precipitation (Aylor 1986). After spore deposition on soybean leaves, various variables such as leaf wetness, temperature, and relative humidity will further affect the establishment of rust (Desborough 1984; Melching et al. 1979).

The escape of $P$. pachyrhizi urediniospores from the substrate to the air above the canopy is a key component in short- and longdistance movement modeling. Parameters involved in this process include strength of inoculum source, escape rate of urediniospores (from infected leaves and the canopy), spore survival during transport, and deposition rates (Isard et al. 2005; Pan et al. 2006; Yang 2006). The amount of urediniospores generated from soybean, susceptible kudzu, and resistant kudzu canopy in Florida was estimated at $6.7 \times 10^{12}, 4.4 \times 10^{12}$, and $7 \times 10^{11}$ urediniospores per day, respectively (Kelly et al. 2015). The application of SRAPS makes multiple assumptions, including that $25 \%$ of the heavily infected source plant releases 6 million urediniospores per day, 33\% of which are released during the optimal transport period and that $15 \%$ of them escape from the soybean canopy (Isard et al. 2005). Accurate estimates of the short-distance movement of urediniospores

TABLE 1. Input variables in the datasets used to compare models of short-distance movement of Phakopsora pachyrhizi urediniospore

\begin{tabular}{ll}
\hline Dataset & \multicolumn{1}{c}{ Input variables } \\
\hline Passive trap & 1. Daily mean temperature $\left({ }^{\circ} \mathrm{C}\right)$ \\
2. Daily mean relative humidity $(\%)$ \\
3. Daily mean precipitation $(\mathrm{mm})$ \\
4. Daily mean wind speed $(\mathrm{km} / \mathrm{h})$ \\
5. Daily mean wind direction $\left({ }^{\circ}\right)$ \\
6. Minimum wind speed $(\mathrm{km} / \mathrm{h})$ \\
7. Maximum wind speed $(\mathrm{km} / \mathrm{h})$ \\
8. Position of trap $\left({ }^{\circ}\right)$ \\
9. Distance (m) \\
10. Difference between trap location and wind $\left({ }^{\circ}\right)$ \\
1. Time of the day \\
2. Hourly mean temperature $\left({ }^{\circ} \mathrm{C}\right)$ \\
3. Hourly mean relative humidity $(\%)$ \\
4. Hourly total precipitation $(\mathrm{mm})$ \\
5. Hourly mean wind speed $(\mathrm{km} / \mathrm{h})$ \\
6. Hourly mean wind direction $\left({ }^{\circ}\right)$ \\
7. Trap height (m) \\
8. Hourly mean leaf wetness $(\mathrm{Centibar})$ \\
9. Hourly mean solar radiation $\left(\mathrm{W} / \mathrm{m}{ }^{2}\right)$ \\
10. Previous hour mean temperature $\left({ }^{\circ} \mathrm{C}\right)$ \\
11. Previous hour mean relative humidity $(\%)$ \\
12. Previous second-hour mean temperature $\left({ }^{\circ} \mathrm{C}\right)$ \\
13. Previous second-hour mean relative humidity $(\%)$ \\
14. Previous 2 -h mean temperature $\left({ }^{\circ} \mathrm{C}\right)$ \\
15. Previous 2 -h mean relative humidity $(\%)$ \\
\hline
\end{tabular}

may be crucial to risk assessments and seasonal soybean rust forecasting.

Understanding how environmental factors influence the early stages of the aerobiological process provides useful information for modeling short-distance spore movement from field to field and long-distance spore movement from within a continent or from continent to continent. One model simulated urediniospore escape from the plant canopy by wind speed to predict urediniospore escape from the boundary layer of the canopy (Andrade et al. 2009). Along with wind speed, the release of $P$. pachyrhizi urediniospores also depends on other environmental factors like humidity, leaf wetness, precipitation, solar radiation, and temperature (Del Ponte et al. 2006b; Isard et al. 2005, 2006a). However, direct evidence of the relationships among these factors and the short-distance transport of rust urediniospores is not known.

Predicting short-distance movement of rust spores with environmental variables involves complex multicollinearity data analyses. Unlike traditional regression methods, machine learning methods can process nonlinear relationships between predictors and a response and can process noisy data with multicollinearity (Garzón et al. 2006; Recknagel 2001).

The absolute shrinkage and selection operator (LASSO) is a wellestablished method that reduces the variance of the coefficient estimates by shrinking the coefficients, some to zero, and thus used for both feature selection and multicollinearity (Oyeyemi et al. 2015). Poisson regression is a commonly used model for analyzing count variables. The zero-inflated Poisson regression model is a modification of the regular Poisson regression model that allows for excessive counts of zero in the data. The central idea of the zero-inflated Poisson regression model is that the data comes from two regimes; one is from counts of zero and the other follows a standard Poisson distribution (Lambert 1997). Random forest model is a tree-based method, in which the data space is recursively partitioned based on the value of one of the predictor variables, such that the observations within a partition become more and more homogeneous (Matsuki et al. 2016). Building multiple decision trees using random samples of data points for each tree and random samples of predictors at each split point, random forest model provides more accuracy than those of any single tree model, and it also may prevent overfitting (Breiman 2001). Neural network models are highly sophisticated pattern recognition systems capable of learning complex relationships. During the neural network learning process, input variables are weighted in various combinations, summed, and passed on to multiple layers. This combination of simple calculations results in the ability of neural network to learn complicated nonlearner relationships (Livingstone et al. 1997).

The objective of our study was to develop empirical models to predict the short-distance transport of $P$. pachyrhizi urediniospores based on environmental variables, using urediniospore count data collected from passive and active spore traps at four environments in the southern United States. Our study compared models using the LASSO, zero-inflated Poisson/regular Poisson model, random forest, and neural network to predict the short-distance transport of P. pachyrhizi urediniospores with environmental variables.

\section{MATERIALS AND METHODS}

Environments. Rust epidemics were monitored in soybean fields at Fairhope, Alabama from 11 to 19 August 2005; Attapulgus, Georgia from 4 to 11 October 2005; and Quincy, Florida from 5 to 12 October and 2 to 12 November 2005. Soybeans at Fairhope and Attapulgus were at growth stages (GS) R6 to R7 and R7 to R8, respectively, and at Quincy-1 at GS R2 and Quincy-2 at GS R4 to R6.

At each environment, a Watchdog 700 weather station (Spectrum Technologies, Inc., Plainfield, IL) logged average temperature $\left({ }^{\circ} \mathrm{C}\right)$, relative humidity $(\%)$, wind speed $(\mathrm{km} / \mathrm{h})$, wind direction $\left({ }^{\circ}\right)$, solar 
insolation (watts $/ \mathrm{m}^{2}$ ), precipitation ( $\mathrm{mm}$ ), and leaf wetness (scale of 0 to 15 , where $0=$ dry and $15=$ wet) at $60 \mathrm{~min}$ intervals.

Passive trap urediniospore collection. A network of 16 passive wind-directional spore traps, modeled after the aeroconiscope (Maddox 1870, 1871), formed two concentric rings around the soybean rust source fields (Supplementary Figs. S1 and S2). Traps were positioned at 15 and $61 \mathrm{~m}$ from the edges of diseased plants in plots at $0^{\circ}$ (north), $45^{\circ}$ (northeast), $90^{\circ}$ (east), $135^{\circ}$ (southeast), $180^{\circ}$ (south), $225^{\circ}$ (southwest), $270^{\circ}$ (west), and $315^{\circ}$ (northwest) orientations. Each trap consisted of a 30-cm length of 10.2-cm-diameter PVC pipe with a $25 \mathrm{~cm} \times 25 \mathrm{~cm} \times 2 \mathrm{~mm}$ tail of plastic sheeting fitted into a slit at one end and oriented perpendicular to the ground. Traps behaved like wind vanes as moving air on the surface of the tail caused traps to rotate on swivel mechanisms orienting the front of the collection cylinder into the wind. Inside each trap, a 7-cm length of 1.9-cm-diameter PVC pipe

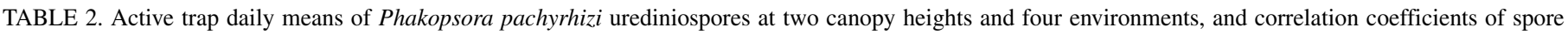
counts within canopy position, temperature, leaf wetness, humidity, precipitation, and wind speed

\begin{tabular}{|c|c|c|c|c|c|c|c|c|c|}
\hline \multirow[b]{2}{*}{ Environment } & \multirow[b]{2}{*}{ Date } & \multirow[b]{2}{*}{ Canopy position } & \multirow[b]{2}{*}{ Mean spores $/ \mathrm{m}^{3}$} & \multicolumn{6}{|c|}{ Correlation $^{\mathrm{a}}$} \\
\hline & & & & Canopy & Temperature & Leaf wetness & Humidity & Precipitation & Wind speed \\
\hline \multirow[t]{16}{*}{ Fairhope } & \multirow[t]{2}{*}{ 11-Aug-05 } & Above & 94.88 & 0.26 & 0.78 & -0.46 & -0.70 & -0.34 & 0.58 \\
\hline & & Within & 181.94 & & -0.33 & 0.74 & 0.40 & 0.81 & -0.50 \\
\hline & \multirow[t]{2}{*}{ 12-Aug-05 } & Above & 100.69 & 0.87 & 0.39 & -0.62 & -0.48 & & 0.69 \\
\hline & & Within & 347.41 & & -0.09 & -0.18 & -0.03 & & 0.27 \\
\hline & \multirow[t]{2}{*}{ 13-Aug-05 } & Above & 178.12 & $0.99 * *$ & $0.88 *$ & $-0.98 * *$ & -0.78 & & 0.80 \\
\hline & & Within & 379.51 & & 0.79 & $-0.94 *$ & -0.67 & & 0.79 \\
\hline & \multirow[t]{2}{*}{ 15-Aug-05 } & Above & 204.91 & 0.86 & 0.27 & 0.34 & -0.76 & 0.46 & $0.98 * *$ \\
\hline & & Within & 549.00 & & 0.18 & 0.40 & -0.53 & 0.48 & 0.79 \\
\hline & \multirow[t]{2}{*}{ 16-Aug-05 } & Above & 11.06 & 0.36 & 0.64 & -0.63 & -0.72 & 0.65 & 0.75 \\
\hline & & Within & 30.77 & & 0.34 & -0.26 & -0.34 & -0.46 & 0.78 \\
\hline & \multirow[t]{2}{*}{ 17-Aug-05 } & Above & 58.11 & $0.93 *$ & -0.25 & -0.29 & -0.05 & -0.01 & -0.81 \\
\hline & & Within & 73.96 & & -0.15 & -0.22 & -0.14 & 0.00 & -0.66 \\
\hline & \multirow[t]{2}{*}{ 18-Aug-05 } & Above & 50.28 & $0.98 * *$ & 0.61 & -0.62 & -0.48 & & 0.67 \\
\hline & & Within & 64.35 & & 0.65 & -0.63 & -0.49 & & 0.66 \\
\hline & 19-Aug-05 & Above & 22.34 & $0.92 *$ & $0.92 *$ & -0.67 & $-0.93^{*}$ & -0.09 & 0.45 \\
\hline & & Within & 23.34 & & 0.78 & -0.72 & -0.82 & -0.29 & 0.34 \\
\hline Attapulgus & $5-O c t-05$ & Above & 303.26 & $0.93 *$ & -0.01 & 0.39 & 0.12 & & 0.23 \\
\hline & & Within & 811.85 & & 0.00 & 0.61 & 0.16 & & 0.38 \\
\hline & $6-O c t-05$ & Above & 38.90 & $0.99 * *$ & 0.79 & -0.82 & -0.77 & $-0.93 *$ & 0.86 \\
\hline & & Within & 118.93 & & 0.87 & $-0.90^{*}$ & -0.85 & $-0.90 *$ & 0.84 \\
\hline & 7-Oct-05 & Above & 16.56 & $0.96^{*}$ & 0.47 & -0.71 & -0.40 & -0.40 & 0.76 \\
\hline & & Within & 51.32 & & 0.65 & -0.64 & -0.60 & -0.26 & 0.73 \\
\hline & $8-O c t-05$ & Above & 32.90 & 0.70 & 0.58 & -0.72 & -0.56 & & 0.64 \\
\hline & & Within & 66.18 & & 0.53 & -0.24 & -0.54 & & 0.49 \\
\hline & 9-Oct-05 & Above & 36.95 & $1.00 * *$ & 0.83 & -0.64 & -0.80 & & 0.17 \\
\hline & & Within & 126.43 & & 0.85 & -0.65 & -0.83 & & 0.20 \\
\hline & 11-Oct-05 & Above & 52.35 & $0.98 * *$ & 0.32 & -0.73 & -0.21 & & 0.45 \\
\hline & & Within & 142.05 & & 0.22 & -0.69 & -0.11 & & 0.42 \\
\hline Quincy-1 & $5-O c t-05$ & Above & 23.51 & $0.90 *$ & -0.10 & 0.79 & 0.12 & 0.81 & 0.19 \\
\hline & & Within & 30.07 & & -0.17 & 0.78 & 0.09 & 0.79 & 0.12 \\
\hline & $6-O c t-05$ & Above & 17.22 & $0.98 * *$ & 0.09 & $-0.97 * *$ & $-0.96 * *$ & & 0.73 \\
\hline & & Within & 25.66 & & 0.22 & $-0.95^{*}$ & $-0.94 *$ & & 0.80 \\
\hline & 7-Oct-05 & Above & 3.79 & 0.59 & 0.81 & -0.58 & $-0.90^{*}$ & & -0.59 \\
\hline & & Within & 7.76 & & 0.12 & 0.24 & -0.49 & & -0.18 \\
\hline & $8-O c t-05$ & Above & 7.98 & 0.80 & 0.53 & & 0.14 & & 0.07 \\
\hline & & Within & 25.76 & & 0.35 & & 0.36 & & 0.06 \\
\hline & 11-Oct-05 & Above & 25.29 & $0.96^{*}$ & $0.93 *$ & $-0.91^{*}$ & -0.87 & & $0.96 *$ \\
\hline & & Within & 93.22 & & 0.82 & -0.78 & -0.77 & & 0.86 \\
\hline & $12-O c t-05$ & Above & 25.65 & 0.77 & 0.21 & -0.08 & -0.24 & & 0.73 \\
\hline & & Within & 97.65 & & 0.05 & -0.26 & 0.02 & & 0.69 \\
\hline Quincy-2 & 2-Nov-05 & Above & 310.12 & $0.89 *$ & -0.35 & & 0.54 & & 0.93 \\
\hline & & Within & $1,106.68$ & & 0.29 & & -0.12 & & 0.50 \\
\hline & 3-Nov-05 & Above & 821.92 & $0.93 *$ & -0.43 & 0.07 & 0.52 & & $0.8^{*}$ \\
\hline & & Within & $2,228.37$ & & -0.57 & 0.23 & 0.64 & & 0.87 \\
\hline & 4-Nov-05 & Above & 557.87 & 0.72 & $0.89^{*}$ & -0.64 & -0.86 & & 0.85 \\
\hline & & Within & $2,961.87$ & & 0.77 & $-0.97 * *$ & -0.83 & & 0.33 \\
\hline & 6-Nov-05 & Above & $1,688.61$ & 0.85 & 0.32 & -0.33 & -0.02 & & $0.97 * *$ \\
\hline & & Within & $6,277.78$ & & 0.66 & -0.69 & -0.30 & & 0.86 \\
\hline & 7-Nov-05 & Above & $2,225.24$ & $0.99 * *$ & $0.97 * *$ & $-0.92 *$ & -0.87 & & 0.41 \\
\hline & & Within & $8,085.50$ & & $0.97 * *$ & $-0.89^{*}$ & -0.84 & & 0.32 \\
\hline & 8-Nov-05 & Above & $1,256.53$ & $0.98 *$ & 0.67 & -0.80 & -0.51 & & $0.99 *$ \\
\hline & & Within & $5,335.04$ & & 0.54 & -0.73 & -0.36 & & $1.00 * *$ \\
\hline & 9-Nov-05 & Above & $1,437.29$ & $0.99 * *$ & 0.81 & -0.76 & -0.76 & & 0.62 \\
\hline & & Within & $3,490.65$ & & 0.80 & -0.78 & -0.73 & & 0.56 \\
\hline & 10-Nov-05 & Above & $9,446.19$ & $0.98 * *$ & $0.89 *$ & -0.83 & -0.73 & & $0.89 *$ \\
\hline & & Within & $16,138.47$ & & $0.90 *$ & -0.86 & -0.75 & & $0.96 * *$ \\
\hline & 11-Nov-05 & Above & $4,125.74$ & 0.92 & -0.88 & & 0.83 & & $0.98 *$ \\
\hline & & Within & $5,956.31$ & & -0.85 & & 0.91 & & 0.89 \\
\hline & 12-Nov-05 & Above & $1,993.88$ & $0.96^{*}$ & -0.86 & 0.82 & 0.85 & & -0.31 \\
\hline & & Within & $4,056.81$ & & $-0.96^{*}$ & $0.92 *$ & $0.94 *$ & & -0.57 \\
\hline
\end{tabular}

a $*=$ significant at $P=0.05$ and $* *=$ significant at $P=0.01$. 
with a $45^{\circ}$ slit cut partially through the pipe was anchored to the bottom inner surface of the trap, serving as a microscope slide holder. Slides were labeled, coated with a thin layer of silicone grease (covering approximately $75 \%$ of the length of the slide; G-697, General Electric Co., Waterford, NY), and seated upright in the slide holder with the greased surface tilted back and facing upwind. The passive spore trapping device was mounted on $1.5 \mathrm{~m}$ (height of trap) $\times 1.9$-cm-diameter PVC pipe, which was slipped over a $1.2 \mathrm{~m} \times 9.5 \mathrm{~mm}$ electric steel fencepost driven into the ground. With this apparatus, air moving through the trap deposited particulates, including rust urediniospores, onto the silicone greasecoated slides. Slides were collected and replaced daily at $1600 \mathrm{~h}$ and stored in microscope slide boxes.

Active trap urediniospore collection. Model 20 Rotorod Samplers (Multidata LLC, St. Louis Park, MN) consisting of a motor, a rotating sampler head, and collector rods were used to actively collect urediniospores. The motor was mounted with zip ties or hose clamps on 2-cm-diameter PVC pipe slipped over metal fence posts driven into the ground, and was powered by a 12-volt battery. The leading edges of clear polystyrene collector rods
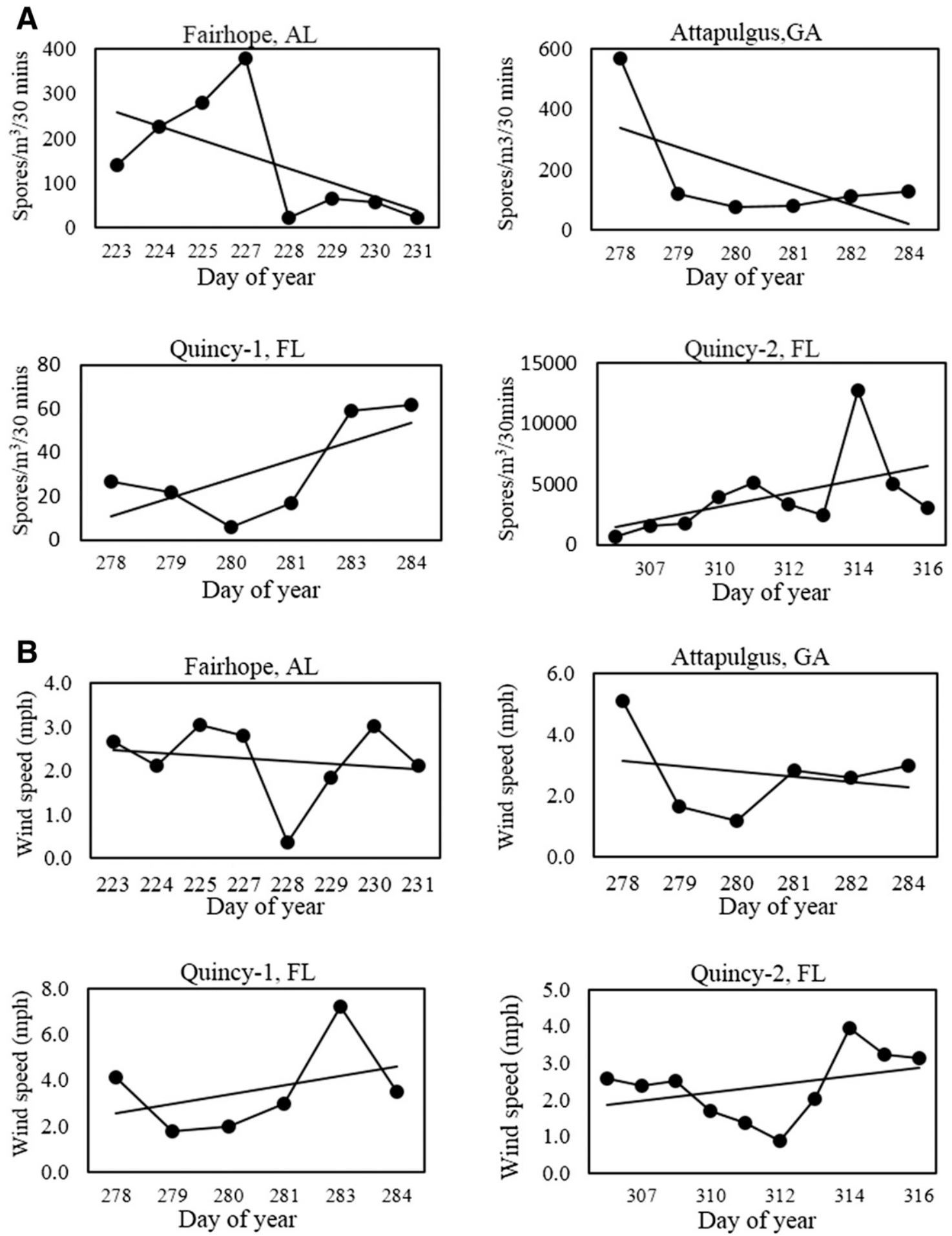

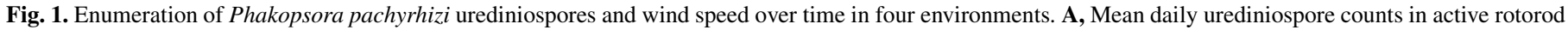
(above and below soybean canopy level) traps. B, Mean daily wind speed. Straight lines represent trend of best linear fit. 
$(1.52 \times 1.52 \times 32 \mathrm{~mm})$ were coated with a thin layer of silicone grease (General Electric Co., Waterford, NY).

At each of the four environments, samplers were erected at two sites (three sites for Fairhope) within the field where actively developing rust lesions were observed. Each site within a field had a pair of samplers located together with one sampler being $25 \%$ above canopy height and the other at $25 \%$ below canopy height. Within the canopy, the sampling head and rods were located above the motor and were inversed for sampling over the canopy. Rotorod heads rotated at 2,400 to 2,440 rpm. Samples were collected daily every $2 \mathrm{~h}$ from 0800 to $1800 \mathrm{~h}$, except at Attapulgus, where the samples were collected at 0830, 1030, 1230, 1430, and $1700 \mathrm{~h}$. Each sampling interval lasted $30 \mathrm{~min}$ and the five sampling times were categorized as morning, midmorning, noon, midafternoon, and late afternoon. Collector rods were subsequently adhered with white Elmer's glue (Elmer's Products, Inc., Columbus, OH) to labeled microscope slides and stored in microscope slide boxes for further examination.

Urediniospore counts. For passive traps, slides were observed through a compound microscope at $200 \times$ magnification. The number of collected urediniospores were enumerated by counting 20 to 60 sample areas (each was $0.58 \mathrm{~mm}^{2}$ ) depending on spore density. The represented area was 11.6 to $34.9 \mathrm{~mm}^{2}$ or 0.65 to $1.96 \%$ of the total $1,775 \mathrm{~mm}^{2}$ greased area. Average number of spores were expressed as urediniospores per square centimeter per day.

For active traps, urediniospores from the entire leading edge surface of each collector rod were visually enumerated by observation under $200 \times$ magnification. Results were reported as number of spores $/ \mathrm{m}^{3}$ of air sampled per $30 \mathrm{~min}$ time interval. To detect differences in active trap heights and times of day, a mixed model analysis was employed (Proc Mixed SAS) on all log-transformed spore counts with trap position and time of day effects as repeated measures. Means were separated by least significant difference at a significance level of $\alpha=0.05$.
Data preparation for model evaluation. The summary statistics including range and quartile of the response variables (spore counts) and all the input variables of both datasets were examined. Response variables were log scaled, adding 0.05 to the counts, to be in similar range as other variables for modeling purposes. The input variables in the passive trap dataset and active trap dataset are listed in Table 1. Correlations were calculated between each pair of variables to check for multicollinearity. For model training and validation, $80 \%$ of the data points were randomly and uniformly selected from each location to serve as a training dataset and $20 \%$ of the data were reserved for testing model performance. Model validation was repeated 10 times, randomly partitioning the datasets 10 times, and the average prediction accuracy for each model was calculated.

LASSO model. A LASSO regression model was implemented with the GLMNET package in R v3.1.1 (R Development Core Team 2008). A "Gaussian" distribution response variable was used due to the presence of continuous output variables in the processed data. Fivefold cross validation was conducted to select the regularization parameter lambda. A LASSO regression model was fitted using the minimized lambda value to predict the spore counts in the testing dataset. After the model was fitted, the variance inflation factor was checked for each variable that remained in the model.

Zero-inflation Poisson/regular Poisson model. This model used the "zeroinfl" function in the pscl package in $\mathrm{R}$ for the passive trap dataset. Only the important variables identified in LASSO model were included to account for multicollinearity. In order to identity potential covariates that affected the probability of being in the all-zero component, analysis of variance was first conducted to compare the means of each predicting variable in the "alwayszero" count group and "nonzero" count group. Variables with significantly different means between the "always-zero" count group and nonzero count group were potential covariates that caused excess zeros and were included in the inflation component portion of the zero-inflated Poisson model. For the active trap
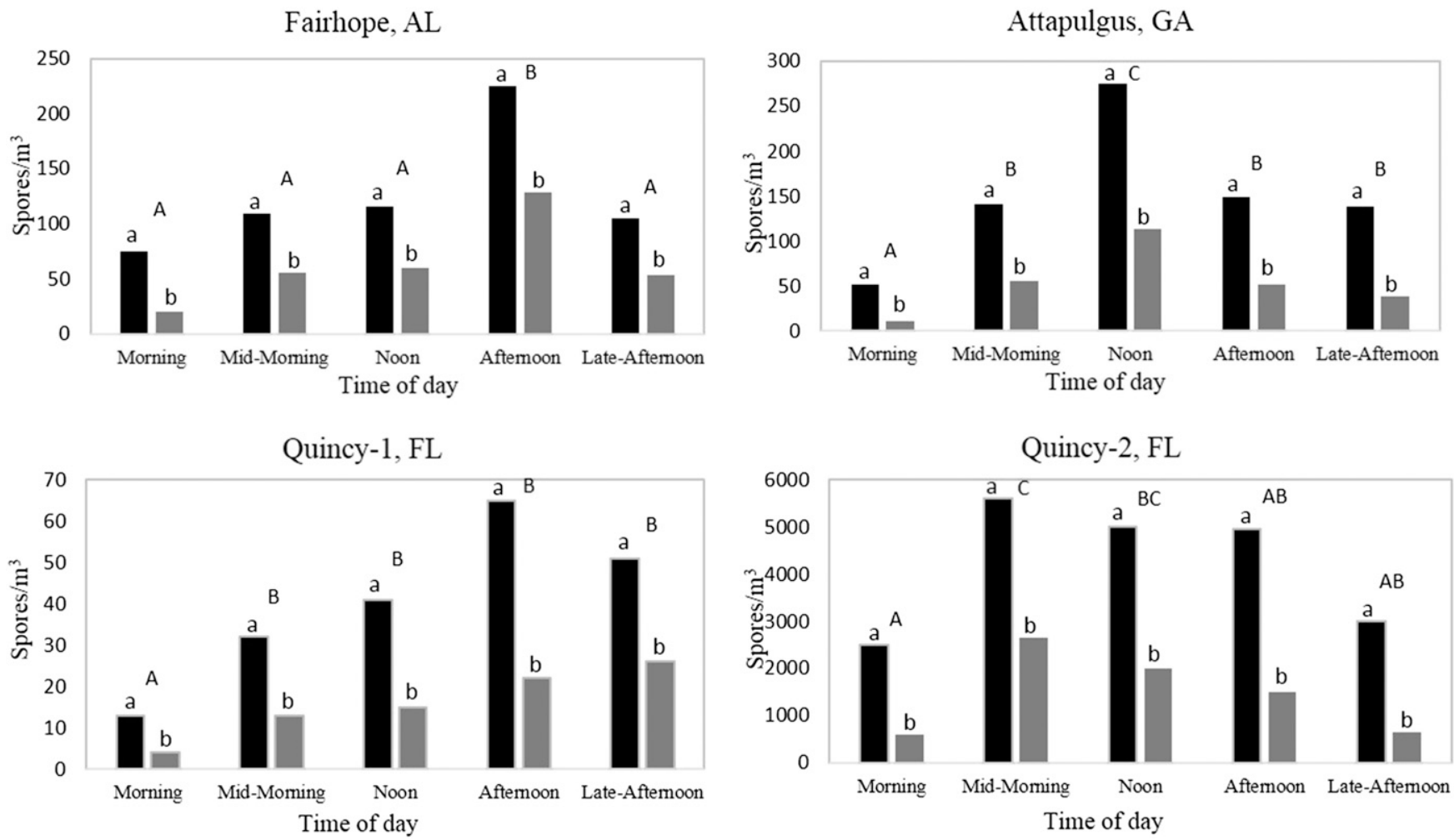

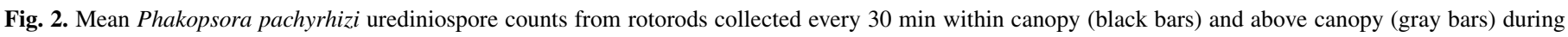

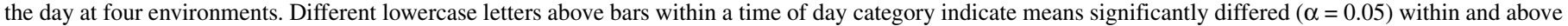
the canopy. Different uppercase letters among time of day categories indicate means significantly differed ( $\alpha=0.05)$ over the categories. 
dataset, a regular Poisson model was fitted using the "glm" function in $\mathrm{R}$ since there were few zero counts.

Random forest model. The random forest model was trained with the training dataset derived from the original data using the "caret" package in R environment. The number of variables (mtry) randomly sampled as candidates for node splitting during the tree growing process was optimized using the train function through fivefold cross validation. The numbers of trees (ntree) induced in the training process were based on a grid search ranging from 300 to 1,000 . Once the model was trained with the optimized number of trees and variables, spore counts in the testing dataset were predicted using the fitted model.

Neural network model. The neural network model also was developed using the "caret" package in R. Parameters considered and tuned in the neural network model were learning rate (learningrate), activation function (act.fct), number of hidden layers and number of neurons in each hidden layer (hidden), and maximum steps for the training of the neural network (stepmax). All input variables were centered and scaled by subtracting the mean from values followed by dividing values by standard deviation. The model was trained by comparing settings at three learning rates $(0.1,0.01$, and 0.001$)$ and at two stepmax $(100,000$ and 1,000,000) factorial combinations. The logistic activation function was used for smoothing the result of the cross product of neurons and the weights. Hidden layer and number of neurons in each hidden layer were optimized using the train function in the caret package through fivefold cross validation. The neural network model was then fitted with the optimized parameters, and spore counts in the testing datasets were predicted using the fitted model.

\section{RESULTS}

A total of 376 daily spore counts were obtained from passive traps at three environments, and 728 hourly data counts were obtained from active traps at four environments. Spore counts ranged from 0 to 43,503 and from 0 to 19,720 for passive trap and active trap datasets, respectively. There were 161 zero counts and 8 extreme high counts $(>30,000)$ in the passive trap dataset, and there were 4 zero counts and 9 extreme high counts $(>10,000)$ in the active trap dataset. All the data points were used to build the predictive models.

Passive trap dataset. The sum of spores over both distances (15 and $61 \mathrm{~m}$ ), all directions (eight traps for each distance), four environments, and all sampling times was over 1.0 million spores $/ \mathrm{m}^{2}$ per day with an average count per location of 42,186 spores per day. The inner ring traps had $69 \%$ of the total number of spores $/ \mathrm{m}^{2}$, while the outer ring had $31 \%$ of the total spores $/ \mathrm{m}^{2}$. Correlation between spore counts and each of the 10 input variables showed that mean daily temperature $(r=-0.565 ; P=0.001)$, mean daily relative humidity $(r=-0.539 ; P=0.001)$, and distance of trap from the source $(r=-0.666 ; P=0.000028)$ were negatively correlated with spore

TABLE 3. Time of day mean spore concentrations in the active traps at both canopy heights and all environments, correlated to within canopy spore concentration, temperature, leaf wetness, humidity, precipitation, and wind speed

\begin{tabular}{|c|c|c|c|c|c|c|c|c|c|}
\hline \multirow[b]{2}{*}{ Environment } & \multirow[b]{2}{*}{ Time of day ${ }^{a}$} & \multirow[b]{2}{*}{ Canopy position } & \multirow[b]{2}{*}{ Mean spores $/ \mathrm{m}^{3}$} & \multicolumn{6}{|c|}{ Correlations $^{\mathrm{b}}$} \\
\hline & & & & Within canopy & Temperature & Leaf wetness & Humidity & Rain & Wind speed \\
\hline \multirow[t]{10}{*}{ Fairhope } & \multirow[t]{2}{*}{ Morning } & Above & 24.53 & $0.93 * *$ & 0.10 & -0.02 & -0.22 & 0.39 & -0.07 \\
\hline & & Within & 75.22 & & -0.16 & 0.24 & 0.01 & 0.31 & -0.37 \\
\hline & \multirow[t]{2}{*}{ Midmorning } & Above & 61.69 & $0.92 * *$ & 0.18 & -0.01 & -0.12 & & 0.52 \\
\hline & & Within & 118.54 & & 0.09 & -0.16 & -0.17 & & 0.25 \\
\hline & \multirow[t]{2}{*}{ Noon } & Above & 71.32 & $0.95 * *$ & 0.06 & & 0.12 & -0.43 & -0.02 \\
\hline & & Within & 120.56 & & 0.25 & & -0.03 & -0.57 & 0.20 \\
\hline & \multirow[t]{2}{*}{ Afternoon } & Above & 139.86 & $0.93 * *$ & 0.50 & $-0.80^{*}$ & -0.56 & & 0.38 \\
\hline & & Within & 226.28 & & 0.24 & -0.59 & -0.32 & & 0.35 \\
\hline & \multirow[t]{2}{*}{ Late afternoon } & Above & 68.68 & $0.93 * *$ & -0.20 & 0.00 & 0.05 & 0.45 & $0.77 *$ \\
\hline & & Within & 106.80 & & -0.23 & 0.24 & 0.04 & 0.51 & 0.61 \\
\hline \multirow[t]{10}{*}{ Attapulgus } & \multirow[t]{2}{*}{ Morning } & Above & 13.02 & $0.93 * *$ & 0.03 & -0.69 & $-0.86^{*}$ & -0.42 & 0.81 \\
\hline & & Within & 62.18 & & -0.16 & -0.57 & -0.78 & -0.19 & 0.75 \\
\hline & \multirow[t]{2}{*}{ Midmorning } & Above & 66.38 & $0.97 * *$ & 0.68 & -0.22 & -0.41 & & 0.79 \\
\hline & & Within & 138.52 & & 0.75 & -0.22 & -0.58 & & 0.69 \\
\hline & \multirow[t]{2}{*}{ Noon } & Above & 119.14 & $0.89 *$ & 0.13 & & -0.43 & & $0.86^{*}$ \\
\hline & & Within & 282.50 & & 0.29 & & -0.40 & & $0.86^{*}$ \\
\hline & \multirow[t]{2}{*}{ Afternoon } & Above & 59.00 & $0.94 * *$ & -0.04 & $-0.96 * *$ & -0.49 & $-0.96 * *$ & $0.85^{*}$ \\
\hline & & Within & 147.86 & & -0.11 & $-0.87 *$ & -0.38 & $-0.87 *$ & $0.96 * *$ \\
\hline & \multirow[t]{2}{*}{ Late afternoon } & Above & 39.37 & $1.00 * *$ & -0.80 & 0.00 & 0.71 & & 0.47 \\
\hline & & Within & 135.47 & & $-0.84 *$ & -0.05 & 0.69 & & 0.50 \\
\hline \multirow[t]{10}{*}{ Quincy-1 } & \multirow[t]{2}{*}{ Morning } & Above & 4.21 & 0.69 & 0.00 & -0.63 & -0.37 & & 0.61 \\
\hline & & Within & 12.59 & & -0.56 & -0.36 & 0.37 & & 0.02 \\
\hline & \multirow[t]{2}{*}{ Midmorning } & Above & 14.20 & $0.84 *$ & -0.67 & -0.47 & -0.07 & & 0.60 \\
\hline & & Within & 32.27 & & $-0.82 *$ & -0.16 & 0.23 & & 0.13 \\
\hline & \multirow[t]{2}{*}{ Noon } & Above & 16.51 & 0.77 & 0.37 & 0.65 & -0.68 & & 0.43 \\
\hline & & Within & 41.48 & & -0.01 & 0.28 & -0.76 & & 0.35 \\
\hline & \multirow[t]{2}{*}{ Afternoon } & Above & 30.72 & $0.89 *$ & -0.12 & 0.16 & -0.58 & & 0.43 \\
\hline & & Within & 67.02 & & -0.40 & -0.19 & $-0.88 *$ & & 0.49 \\
\hline & \multirow[t]{2}{*}{ Late afternoon } & Above & 39.02 & 0.67 & 0.08 & 0.44 & 0.49 & 0.39 & 0.04 \\
\hline & & Within & 53.25 & & -0.34 & 0.68 & 0.23 & 0.67 & 0.75 \\
\hline Quincy-2 & Morning & Above & 592.91 & $0.84 * *$ & -0.18 & -0.03 & -0.03 & & $0.74^{*}$ \\
\hline & & Within & $2,250.90$ & & -0.26 & 0.22 & 0.34 & & 0.59 \\
\hline & Midmorning & Above & $2,684.59$ & $0.92 * *$ & -0.32 & -0.17 & 0.07 & & 0.41 \\
\hline & & Within & $5,592.45$ & & -0.19 & -0.09 & 0.31 & & 0.11 \\
\hline & Noon & Above & $2,048.23$ & $0.96 * *$ & 0.17 & 0.31 & 0.47 & & -0.03 \\
\hline & & Within & $4,841.73$ & & 0.26 & 0.40 & 0.52 & & -0.18 \\
\hline & Afternoon & Above & $1,625.60$ & $0.95 * *$ & 0.11 & & 0.33 & & 0.62 \\
\hline & & Within & $4,462.24$ & & 0.15 & & 0.54 & & 0.63 \\
\hline & Late afternoon & Above & 802.88 & $0.75^{*}$ & -0.03 & 0.25 & -0.10 & & 0.54 \\
\hline & & Within & $3,144.28$ & & -0.07 & 0.41 & 0.44 & & 0.19 \\
\hline
\end{tabular}

${ }^{a}$ Morning, 0800 to $0830 \mathrm{~h}$; midmorning, 1000 to $1030 \mathrm{~h}$; noon, 1200 to $1230 \mathrm{~h}$; afternoon, 1400 to $1430 \mathrm{~h}$; and late afternoon, 1600 to $1630 \mathrm{~h}$.

$\mathrm{b} *=$ significant at $P=0.05$ and $* *=$ significant at $P=0.01$. 
counts while minimum daily wind speed $(r=0.593 ; P=0.02)$ was positively correlated with spore counts.

Active trap dataset. Spore numbers within the canopy were significantly correlated to those above the canopy in all environments on 19 of the 30 days monitored, and the spore counts within the canopy were higher than those above the canopy (Table 2). Temperature was positively related to spore counts on 8 of the 30 days. We observed 9 and 4 days when spore counts were significantly negatively correlated with leaf wetness and humidity, respectively. One significant correlation in opposition to general trends was detected on 12 November 2005 at Quincy-2, when the highest spore count was correlated with low temperature, high leaf wetness, and high humidity. There were only a few precipitation events during the sampling period, but significant correlations with spore counts were negative. Wind speed and spore count were significantly positively correlated on 9 of the 30 days.

There was considerable variation in the numbers of $P$. pachyrhizi urediniospores in the traps at the four locations. The trend lines for urediniospore counts at Fairhope and Attapulgus decreased over time while the trend line for counts at Quincy-1 and Quincy-2 increased (Fig. 1A). Along with the correlated variables temperature, humidity, leaf wetness, and precipitation (Table 2), mean daily spore counts in the traps were correlated with wind speed during the same time period (Fig. 1B).

Spore counts tended to be lower in the morning and increased throughout the day until afternoon or late afternoon (Fig. 2). Average spore counts from the active traps for each time of day in each environment and corresponding environmental variables were also correlated (Table 3). Seventeen of the 20 correlations between within canopy and above canopy data were positive and significant. The exceptions to this trend occurred at Quincy-1 where spore counts were low. There were no significant positive correlations of spore counts with temperature, leaf wetness, or humidity. Correlations of temperature, leaf wetness, and humidity with spore counts were negative and significant for two, three, and two occasions, respectively.

LASSO regression. Cross validation identified the optimized smoothing parameter lambda, which ranged from 0.05 to 0.17 with
7 to 4 variables in the model for the passive trap dataset, and ranged from 0.007 to 0.05 with 13 to 9 variables in the model for the active trap dataset (Supplementary Figs. S3). The variables that significantly contributed to the spore count at lambda $=0.05$ for the passive trap dataset in decreasing order of importance were mean daily temperature, mean daily wind speed, mean daily wind direction, max and minimum wind speed, precipitation, position of trap, mean daily relative humidity, distance from source, and degree between trap and wind direction (Table 4). Variables that significantly contributed to active trap spore counts at lambda $=0.007$ for the active trap dataset in decreasing order of importance were precipitation, height of trap, time of the day, mean previous 2-h temperature, previous second-hour temperature, mean hourly wind speed, mean hourly temperature, mean hourly relative humidity, previous hour temperature, leaf wetness, mean hourly wind direction, solar radiation, and previous hour humidity (Table 4).

Selected variables used to fit the regression model and predict spore counts in the testing dataset explained 48.2 and $47.3 \%$ of the variation for the passive dataset and active dataset, respectively (Fig. 3). The prediction accuracy of the LASSO regression model evaluated by 10 repeats of validation ranged from 0.28 to 0.71 for the passive trap dataset, and 0.61 to 0.70 for the active trap dataset (Table 5). The average prediction accuracy was 0.56 and 0.65 for the passive and active trap dataset, respectively.

Zero-inflation Poisson/regular Poisson model. Daily maximum wind speed and temperature were the only variables that were significantly different between the "always-zero" group and the "nonzero" group (Supplementary Table S1A), therefore, these two variables were included in the inflation component portion. All the predictors included in the Poisson count portion of the zeroinflated Poisson model were statistically significant for the passive trap dataset $(P<0.0001)$, and daily maximum wind speed in the inflation component portion was also significant $(P=0.0323)$ (Supplementary Table S1B). The estimated odds of "excess zero" was about $\exp (-0.11)=0.89$ times lower when the wind speed increased by one unit. All parameters included in the Poisson model for the active trap dataset were significant $(P<0.0001)$. The prediction accuracy of the zero-inflated Poisson model evaluated by

TABLE 4. Relative importance of variables as identified by the absolute shrinkage and selection operator regression (LASSO), random forest, and neural network models $^{\mathrm{a}}$

\begin{tabular}{|c|c|c|c|c|c|c|}
\hline \multirow[b]{2}{*}{ Dataset } & \multicolumn{2}{|l|}{ Lasso regression } & \multicolumn{2}{|l|}{ Random forest } & \multicolumn{2}{|l|}{ Neural network } \\
\hline & Variables & $\begin{array}{c}\text { Relative } \\
\text { importance }(\%)\end{array}$ & Variables & $\begin{array}{c}\text { Relative } \\
\text { importance }(\%)\end{array}$ & Variables & $\begin{array}{c}\text { Relative } \\
\text { importance }(\%)\end{array}$ \\
\hline \multirow{10}{*}{$\begin{array}{c}\text { Passive } \\
\text { trap }\end{array}$} & Mean daily wind speed & 100.0 & Mean daily temperature & 100.0 & Mean daily temperature & 100.0 \\
\hline & Mean daily temperature & 56.0 & Mean daily wind speed & 67.5 & Min wind speed & 48.4 \\
\hline & Mean daily wind direction & 18.6 & Mean daily wind direction & 34.8 & Mean daily wind speed & 46.3 \\
\hline & Distance from source & 15.5 & Max wind speed & 32.1 & Distance from source & 38.2 \\
\hline & Min wind speed & 13.3 & Min wind speed & 28.8 & Mean daily relative humidity & 35.8 \\
\hline & Mean daily relative humidity & 6.0 & Precipitation & 19.7 & Precipitation & 6.9 \\
\hline & Max wind speed & 5.3 & Position of trap & 14.9 & Max wind speed & 6.4 \\
\hline & Position of trap & 0.0 & Mean daily relative humidity & 13.6 & Mean daily weed direction & 3.0 \\
\hline & Precipitation & 0.0 & Distance from source & 13.2 & Degree between trap and wind & 2.6 \\
\hline & Degree between trap and wind & 0.0 & Degree between trap and wind & 4.2 & Position of trap & 0.0 \\
\hline \multirow{15}{*}{$\begin{array}{l}\text { Active } \\
\text { trap }\end{array}$} & Precipitation & 100.0 & Mean hourly relative humidity & 100.0 & Mean hourly relative humidity & 100.0 \\
\hline & Height of trap & 27.5 & Mean previous 2-h temperature & 69.7 & Mean previous 2-h temperature & 92.8 \\
\hline & Time of the day & 3.9 & Mean hourly temperature & 54.8 & Previous hour humidity & 78.6 \\
\hline & Mean previous 2 -h temperature & 3.8 & Mean hourly wind direction & 48.5 & Mean hourly wind direction & 71.4 \\
\hline & Previous second-hour temperature & 3.6 & Previous second-hour temperature & 43.0 & Previous second-hour temperature & 68.7 \\
\hline & Mean hourly wind speed & 2.6 & Previous hour humidity & 38.3 & Mean previous two-hour humidity & 68.4 \\
\hline & Mean hourly temperature & 2.6 & Solar radiation & 36.8 & Mean hourly temperature & 62.8 \\
\hline & Mean hourly relative humidity & 1.6 & Mean hourly wind speed & 31.8 & Previous hour temperature & 55.5 \\
\hline & Previous hour temperature & 1.4 & Previous hour temperature & 30.4 & Previous second-hour humidity & 52.3 \\
\hline & Leaf wetness & 1.3 & Mean previous 2-h humidity & 27.4 & Height of trap & 45.2 \\
\hline & Mean hourly wind direction & 1.1 & Time of the day & 25.9 & Solar radiation & 38.5 \\
\hline & Solar radiation & 0.9 & Previous second-hour humidity & 20.1 & Mean hourly wind speed & 11.7 \\
\hline & Previous hour humidity & 0.5 & Height of trap & 15.7 & Time of the day & 4.3 \\
\hline & Previous second-hour humidity & 0.0 & Leaf wetness & 11.7 & Leaf wetness & 2.5 \\
\hline & Previous 2-h humidity & 0.0 & Precipitation & 1.4 & Precipitation & 0.0 \\
\hline
\end{tabular}

a Relative importance of variables importance was determined using the "varImp" function in the caret package in R, and all the measures of importance were scaled to a maximum value of 100 . 
Passive Spore Counts vs Predicted Spore Counts

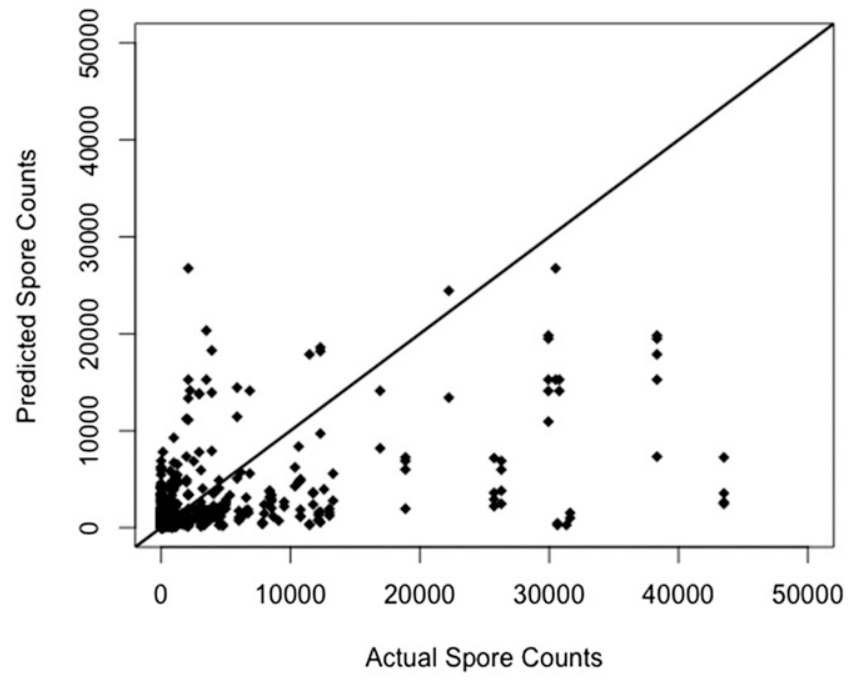

B

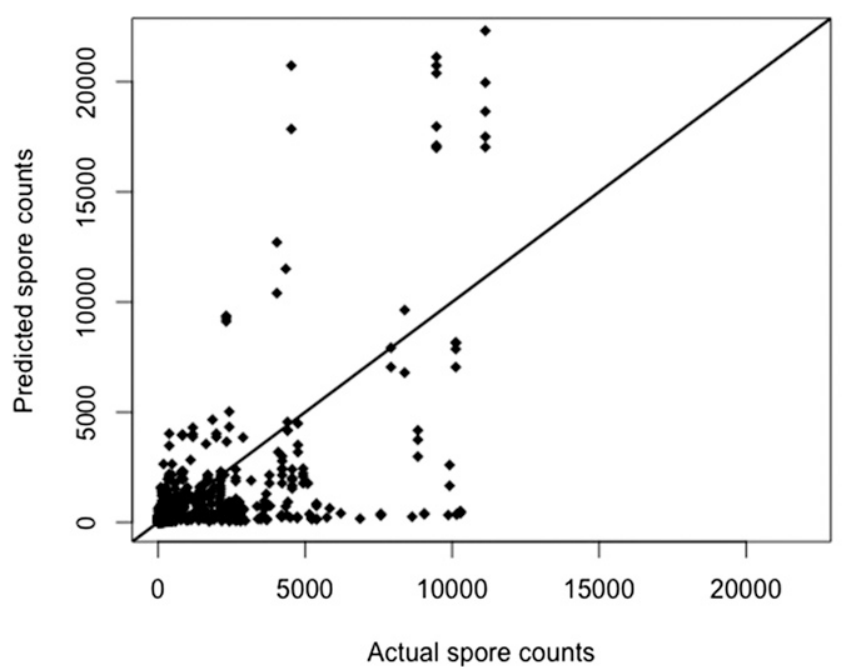

Fig. 3. Phakopsora pachyrhizi urediniospore counts predicted by the absolute shrinkage and selection operator regression (LASSO) regression model versus actual spore counts. A, Actual spore counts and the predicted spore counts in the plot were a combination of the actual and predicted values generated in the validation process for the passive trap dataset. B, Actual spore counts and the predicted spore counts in the plot were a combination of the actual and predicted values generated in the validation process for the active trap dataset.
10 repeats of validation ranged from 0.73 to 0.83 for the passive trap dataset, and the average prediction accuracy was 0.77 . The prediction accuracy of the regular Poisson model evaluated by 10 repeats of validation ranged from and 0.69 to 0.82 for the active trap dataset, and 0.74 for the passive and active trap dataset (Table 5). The predicted values of the 10 testing datasets by the zero-inflation Poisson/regular Poisson model were plotted against the actual spore counts values for the passive trap and active trap datasets (Fig. 4).

Random forest. The optimized number of variables used at each node split in the final random forest model was $\mathrm{m}=6$ and $\mathrm{m}=14$ for the passive and active trap datasets, respectively (Supplementary Fig. S4), and 400 trees minimized the mean square error of the random forest model for both datasets. The final model explained 76.1 and $86.8 \%$ of the total variation for passive and active trap datasets, respectively. The predicted values of the 10 testing datasets using the random forest model were plotted against the actual spore count values for the passive trap and active trap datasets (Fig. 5). The prediction accuracy of the random forest model evaluated by 10 repeats of validation ranged from 0.75 to 0.86 for the passive trap dataset, and 0.93 to 0.95 for the active trap dataset (Table 5). The average prediction accuracy was 0.80 and 0.94 for the passive and active trap dataset, respectively. In decreasing order of importance, the variables contributing to the model were mean daily temperature, minimum wind speed, mean daily wind direction, maximum and minimum wind speed, precipitation, position of trap, mean daily relative humidity, distance from source, and degree between trap and wind (Table 4). For the active trap dataset, variables contributing to the model in decreasing order of importance were mean hourly relative humidity, previous 2-h mean temperature, mean hourly temperature, mean hourly wind direction, previous second-hour mean temperature, previous hour humidity, solar radiation, wind speed, previous hourly mean temperature, mean previous 2-h humidity, time of the day, previous second-hour humidity, height of trap, hourly mean leaf wetness, and hourly total precipitation (Table 4). Like the LASSO regression model, the most important factors affecting the amount of rust spores in the air were temperature, previous hour temperature, wind speed, wind direction, humidity, and time of the day.

Neural network. The optimal parameters for the neural network model selected by fivefold cross validation included one hidden layer with 14 and 19 neurons for the passive and active trap datasets, respectively (Supplementary Fig. S5). The model converged relatively fast with learning rate $=0.001$ and maximum step of stopping learning $=1,000,000$. The predicted values of the 10 testing datasets by the neural network model were plotted against the actual spore counts values for the passive trap and active trap datasets (Fig. 6). The prediction accuracy of the neural network model evaluated by 10 repeats of validation ranged from 0.76 to 0.83 for the passive trap

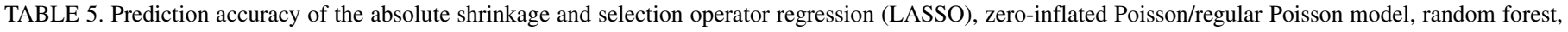
and neural network models in 10 validation processes for the passive and active trap datasets ${ }^{\mathrm{a}}$

\begin{tabular}{|c|c|c|c|c|c|c|c|c|}
\hline \multirow[b]{2}{*}{ Validation process } & \multicolumn{4}{|c|}{ Passive trap dataset } & \multicolumn{4}{|c|}{ Active trap dataset } \\
\hline & LASSO & Zero-inflated Poisson & Random forest & Neural network & LASSO & Poisson & Random forest & Neural network \\
\hline 1 & 0.50 & 0.75 & 0.78 & 0.81 & 0.28 & 0.76 & 0.94 & 0.67 \\
\hline 2 & 0.28 & 0.77 & 0.83 & 0.77 & 0.50 & 0.76 & 0.93 & 0.57 \\
\hline 3 & 0.59 & 0.77 & 0.85 & 0.77 & 0.59 & 0.73 & 0.93 & 0.60 \\
\hline 4 & 0.42 & 0.79 & 0.88 & 0.76 & 0.42 & 0.75 & 0.94 & 0.66 \\
\hline 5 & 0.53 & 0.79 & 0.78 & 0.78 & 0.53 & 0.83 & 0.94 & 0.58 \\
\hline 6 & 0.72 & 0.83 & 0.91 & 0.77 & 0.72 & 0.70 & 0.94 & 0.58 \\
\hline 7 & 0.72 & 0.74 & 0.82 & 0.76 & 0.72 & 0.72 & 0.94 & 0.66 \\
\hline 8 & 0.63 & 0.74 & 0.82 & 0.83 & 0.62 & 0.70 & 0.95 & 0.71 \\
\hline 9 & 0.65 & 0.79 & 0.81 & 0.79 & 0.65 & 0.73 & 0.94 & 0.68 \\
\hline 10 & 0.65 & 0.73 & 0.82 & 0.83 & 0.53 & 0.69 & 0.93 & 0.60 \\
\hline Avg. & 0.56 & 0.77 & 0.83 & 0.79 & 0.65 & 0.74 & 0.94 & 0.63 \\
\hline
\end{tabular}

a In each validation, $80 \%$ of the data points were randomly and uniformly selected from each location and used as a training dataset; $20 \%$ of the data were saved for testing model performance. Prediction accuracy was represented as the correlation coefficients between the predicted and the actual spore counts. 
dataset, and from 0.57 to 0.71 for the active trap dataset (Table 5). The average prediction accuracy was 0.79 and 0.63 for the passive and active trap dataset, respectively. The neural network model indicated that the most important predictor variables associated with spore counts in the passive traps in decreasing order were mean daily temperature, minimum wind speed, mean daily wind speed, distance from source, mean daily relative humidity, precipitation, maximum wind speed, mean daily wind direction, degree between trap and wind, and position of trap (Table 4). The variables that significantly contributed to the spore count for the passive trap dataset in decreasing order of importance were mean daily temperature, mean daily relative humidity, distance from source, minimum wind speed, maximum wind speed, mean daily wind direction, position of the trap, precipitation, mean daily wind speed, degree between trap, and wind direction (Table 4). Variables that significantly contributed to active trap spore counts for the active trap dataset in decreasing order were mean hourly relative humidity, mean previous 2-h temperature, previous hour humidity, mean hourly wind direction,

\section{A Passive Spore Counts vs Predicted Spore Counts}

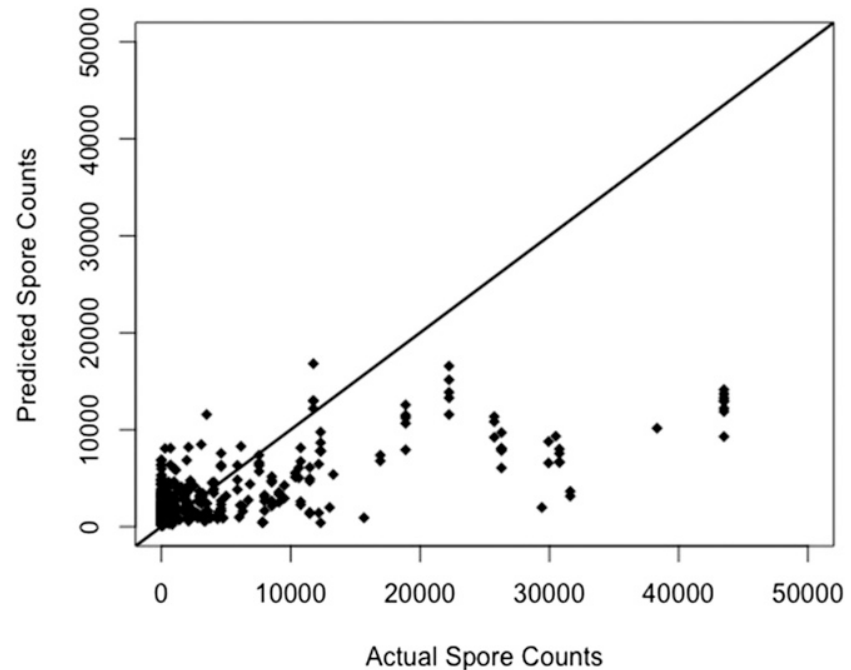

B Active Spore Counts vs Predicted Spore Counts

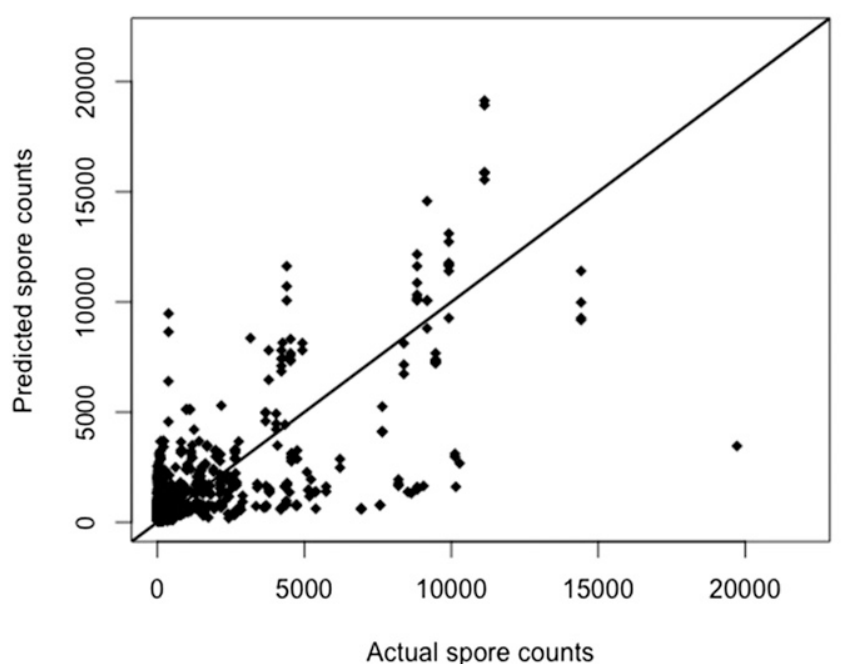

Fig. 4. Phakopsora pachyrhizi urediniospore counts predicted by the zeroinflation Poisson/regular Poisson model versus actual spore counts. A, Actual spore counts and the predicted spore counts in the plot were a combination of the actual and predicted values generated in the validation process for the passive trap dataset. B, Actual spore counts and the predicted spore counts in the plot were a combination of the actual and predicted values generated in the validation process for the active trap dataset. previous second-hour temperature, mean previous 2-h humidity, mean hourly temperature, previous hour temperature, previous second-hour humidity, height of trap, solar radiation, mean hourly wind speed, time of day, and leaf wetness (Table 4).

\section{DISCUSSION}

The short-distance movement of the $P$. pachyrhizi urediniospores from infected soybean leaves to the surrounding air determines the inoculum availability for short- and long-distance spore dispersion and is dependent on many factors. Our results showed that temperature, wind speed, wind direction, relative humidity, leaf wetness, time of the day, and distance from the source were the most important factors that affected urediniospore movement. There were positive correlations between the number of urediniospores with temperature and wind speed, and negative correlations between number of urediniospores with humidity, leaf wetness,
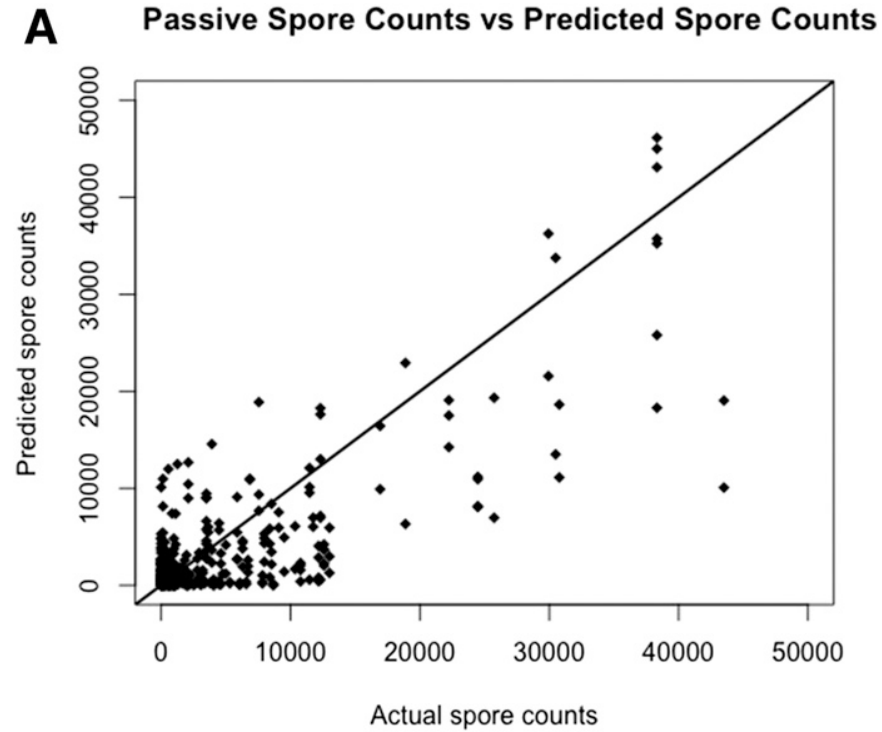

B Active Spore Counts vs Predicted Spore Counts

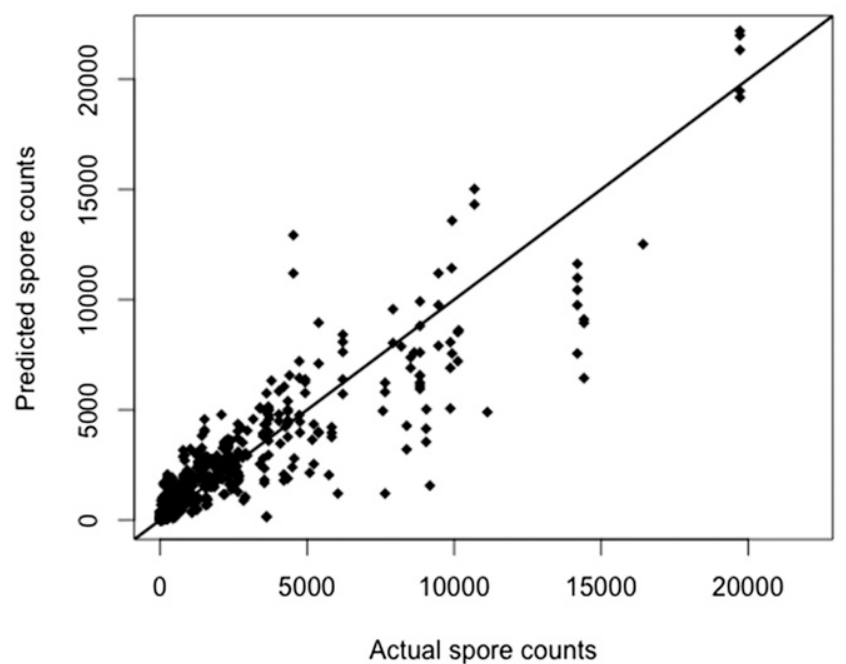

Fig. 5. Phakopsora pachyrhizi urediniospore counts predicted by the random forest model versus actual spore counts. A, Actual spore counts and the predicted spore counts in the plot were a combination of the actual and predicted values generated in the validation process for the passive trap dataset. B, Actual spore counts and the predicted spore counts in the plot were a combination of the actual and predicted values generated in the validation process for the active trap dataset. 
and precipitation. These factors in combination resulted in a majority of the urediniospores collected between midday to midafternoon. Along with these factors, there may be additional biological explanations for higher spore counts around midday. In other studies, it was shown that Puccinia striiformis produces a mucilaginous layer around its spores that becomes thicker as relative humidity increases (Rapilly 1979), which may also be the case for P. pachyrhizi (Del Ponte et al. 2006b), resulting in fewer numbers of spores released into the air.

It is not uncommon for fungi to have a diurnal pattern of peak spore release. Similar to what was found in our study, this was shown for capture of Podosphaera clandestina (powdery mildew of sweet cherry) conidia, where spore numbers peaked about midday, which was positively correlated with wind speed and temperature, but negatively correlated to relative humidity (Grove 1998). In another example, a diurnal pattern was shown for peanut rust as spore capture peaked at noon, which was positively correlated to relative humidity

\section{A Passive Spore Counts vs Predicted Spore Counts}

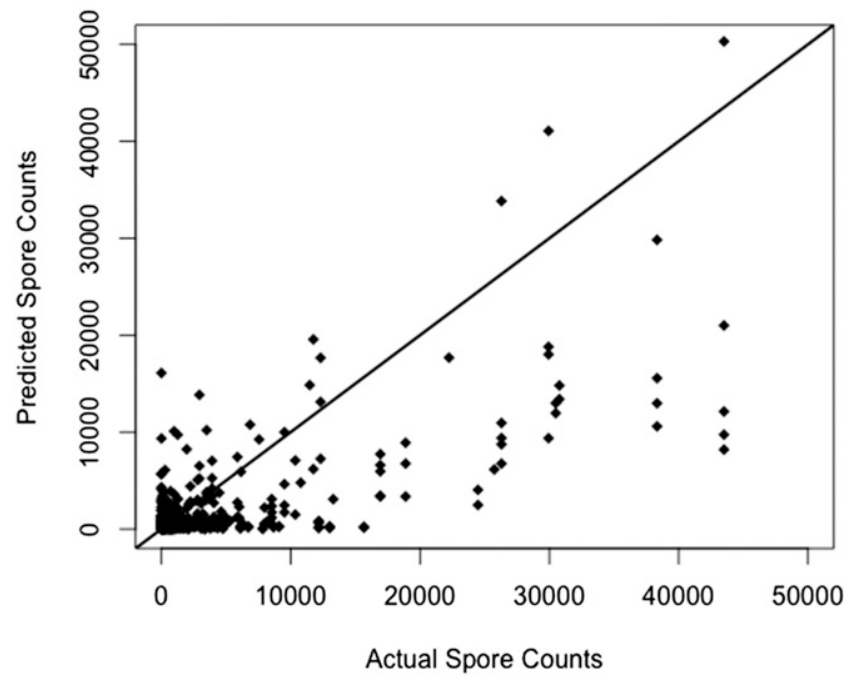

B Active Spore Counts vs Predicted Spore Counts

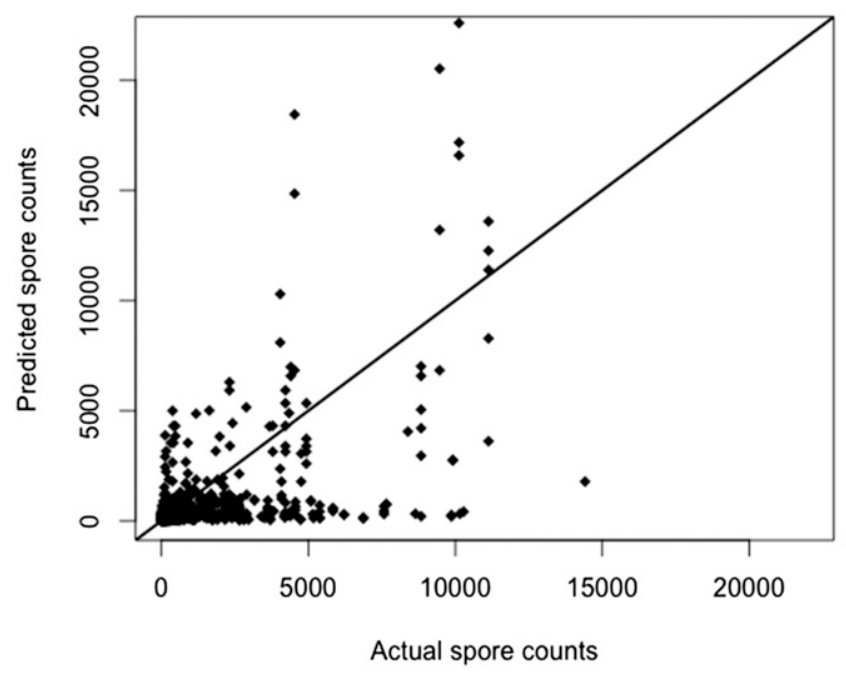

Fig. 6. Phakopsora pachyrhizi urediniospore counts predicted by the neural network model versus actual spore counts. A, Actual spore counts and the predicted spore counts in the plot were a combination of the actual and predicted values generated in the validation process for the passive trap dataset. B, Actual spore counts and the predicted spore counts in the plot were a combination of the actual and predicted values generated in the validation process for the active trap dataset. below $70 \%$ and to increased wind speed (Savary and Janeau 1986). In the case of $P$. pachyrhizi, newly formed urediniospores push older spores upward often forming a chain under still conditions. When the chain is disturbed, the urediniospores become airborne. As the spore chain gets longer, more urediniospores are released into the air.

Precipitation events are generally perceived to wash spores from the atmosphere down to surfaces, including plant leaves. One report showed that precipitation washed $P$. pachyrhizi urediniospores from the leaves and out of the atmosphere (Dufault et al. 2010), but several reports indicate that rain events may disperse $P$. pachyrhizi urediniospores by rain splash (Del Ponte and Esker 2008; Melching et al. 1979). In our study, there were only a few precipitation events and trends related to precipitation were not easily discerned, although when precipitation occurred, it was associated with a reduction in urediniospore counts. However, precipitation and high moisture conditions are known to be important in soybean rust epidemics as shown in several soybean field studies with P. pachyrhizi in Brazil (Del Ponte et al. 2006b), China (Tan et al. 1996), Taiwan (Tschanz and Wang 1980), and Uganda (Kawuki et al. 2004), where precipitation events resulted in higher rust severity after the event. Another key role played by precipitation is providing the leaf wetness necessary for urediniospore germination.

Disease forecasting models provide a way to predict the risk of disease. Regression models have been widely used to predict epidemics of plant diseases including soybean rust (Del Ponte et al. 2006a; Olatinwo et al. 2008; Paul and Munkvold 2005; Rosso and Hansen 2003; Uddin et al. 2003). Regression models have the advantage of simplicity and easy interpretation of predicted results. However, when response and predicting variables have relationships that are more complex than linear, other approaches such as random forest and neural network have been used in making more accurate predictions in many areas, including plant disease epidemiology (Behmann et al. 2015; Mehra et al. 2016; Paul and Munkvold 2005). In our datasets, there were many significant interactions detected between variables. The higher prediction accuracy of the random forest and neural network models over the linear model for predicting urediniospores counts in the traps shows the power of the nonlinear models to help explain these complex interactions.

Our study developed and compared four machine learning models for the prediction of short-distance movement of soybean rust urediniospores. The random forest produced more accurate predictions than the LASSO regression model, the zero-inflated Poisson model, and the neural network model indicating that the relationships between the number of urediniospores released from the leaf surface into the air and the various meteorological variables are more complex than simply linear, and demonstrated the robustness of the random forest model to handle multicollinearity and inflated-zero issues. These four models all identified temperature, humidity, wind speed, wind direction, and leaf wetness as key factors affecting the rust urediniospores collected by the passive and active spore traps. The random forest and neural network models provide a way to analyze nonlinear relationships between variables (Olden et al. 2008; Siroky 2009). However, it can be difficult to interpret the relationships between variables identified by these models due to the lack of simple representation, such as a linear formula. In addition, the values of many parameters in both random forest and neural network models are highly influential. The number of trees and number of variables used at each node in the random forest model and the learning rate, activation function, number of hidden layers, and number of neurons in each layer can greatly affect prediction accuracy.

Overall, we conclude that using multiple machine learning techniques was helpful, not only to identify the most important variables and make the most accurate predictions, but also to increase confidence for applying these models to obtain coherent results. The models built in our study were useful to explain the number of P. pachyrhizi urediniospores found a short distance from the source, which in turn may be useful to build relevant models that are used to advise producers. 


\section{ACKNOWLEDGMENTS}

We thank L. Beck, M. Miles, and T. Steinlage for their assistance in setting up experiments and collecting data. We thank B. Kemerait, J. Marois, and E. Sikora, respectively, for arranging university experiment station space at Attapulgus (Georgia), Quincy (Florida), and Fairhope (Alabama). We also thank T. Herman for edits and comments on this manuscript.

\section{LITERATURE CITED}

Andrade, D., Pan, Z., Dannevik, W., and Zidek, J. 2009. Modeling soybean rust spore escape from infected canopies: Model description and results. J. Appl. Meteorol. Climatol. 48:789-803.

Aylor, D. E. 1986. A framework for examining inter-regional aerial transport of fungal spores. Agric. For. Meteorol. 38:263-288.

Aylor, D. E. 1999. Biophysical scaling and the passive dispersal of fungus spores: Relationship to integrated pest management strategies. Agric. For. Meteorol. 97:275-292

Behmann, J., Mahlein, A. K., Rumpf, T., Römer, C., and Plümer, L. 2015. A review of advanced machine learning methods for the detection of biotic stress in precision crop protection. Precis. Agric. 16:239-260.

Breiman, L. 2001. Random forests. Mach. Learn. 45:5-32.

Christiano, R., and Scherm, H. 2007. Quantitative aspects of the spread of the Asian soybean rust in the southeastern United States, 2005 to 2006. Phytopathology 97:1428-1433.

Del Ponte, E. M., and Esker, P. D. 2008. Meteorological factors and Asian soybean rust epidemics-A system approach and implications for risk assessment. Sci. Agric. 65:88-97.

Del Ponte, E. M., Godoy, C. V., Canteri, M. G., Reis, E. M., and Yang, X. B. 2006a. Models and applications for risk assessment and prediction of Asian soybean rust epidemics. Fitopatol. Bras. 31:533-544.

Del Ponte, E. M., Godoy, C. V., Li, X., and Yang, X. B. 2006b. Predicting severity of Asian soybean rust with empirical rainfall models. Phytopathology 96:797-803.

Desborough, P. J. 1984. Selection of soybean cultivar and sowing date as a strategy for avoidance of rust (Phakopsora pachyrhizi Syd.) losses in coastal New South Wales. Aust. J. Exp. Agric. 24:433-439.

Dufault, N., Isard, S., Marois, J., and Wright, D. 2010. Removal of wet deposited Phakopsora pachyrhizi urediniospores from soybean leaves by subsequent rainfall. Plant Dis. 94:1336-1340.

Garzón, M. B., Blazek, R., Neteler, M., de Dios, R. S., Ollero, H. S., and Furlanello, C. 2006. Predicting habitat suitability with machine learning models: The potential area of Pinus sylvestris L. in the Iberian Peninsula. Ecol. Modell. 197:383-393.

Gregory, P. H. 1973. The Microbiology of the Atmosphere. Wiley, New York.

Grove, G. G. 1998. Meteorological factors affecting airborne conidia concentrations and the latent period of Podosphaera clandistina on sweet cherry. Plant Dis. 82:741-746.

Hartman, G. L., Sikora, E. F., and Rupe, J. C. 2015. Rust. Pages 56-59 in: Compendium of Soybean Diseases and Pests. G. L. Hartman, E. F. Sikora, and J. C. Rupe, eds. American Phytopathological Society, St. Paul, MN.

Hartman, G. L., Wang, T. C., and Tschanz, A. T. 1991. Soybean rust development and the quantitative relationship between rust severity and soybean yield. Plant Dis. 75:596-600.

Isard, S. A., Barnes, C. W., Hambleton, S., Ariatti, A., Russo, J. M., Tenuta, A., Gay, D. A., and Szabo, L. J. 2011. Predicting seasonal soybean rust incursions into the North American continental interior using sentinel plot monitoring, spore trapping, and aerobiological modeling. Plant Dis. 95:1346-1357.

Isard, S. A., Dufault, N. S., Miles, M. R., Hartman, G. L., Russo, J. M., De Wolf, E. D., and Morel, W. 2006a. The effect of solar irradiance on the mortality of Phakopsora pachyrhizi urediniospores. Plant Dis. 90:941-945.

Isard, S. A., and Gage, S. H. 2001. Flow of Life in the Atmosphere: An Airscape Approach to Understanding Invasive Organisms. Michigan State University Press, East Lansing, MI.

Isard, S. A., Gage, S. H., Comtois, P., and Russo, J. M. 2005. Principles of the atmospheric pathway for invasive species applied to soybean rust. BioScience 55:851-861.

Isard, S. A., Russo, J. M., and Ariatti, A. 2007. The Integrated Aerobiology Modeling System applied to the spread of soybean rust into the Ohio River valley during September 2006. Aerobiologia 23:271-282.

Isard, S. A., Russo, J. M., and DeWolf, E. D. 2006b. The establishment of a national pest information platform for extension and education. Published online. Plant Health Progress. doi:10.1094/PHP-2006-0915-01-RV

Kalnay, E. 1996. The NCEP/NCAR 40-year reanalysis project. Bull. Am. Meteorol. Soc. 82:247-279.

Kanamitsu, M., Ebisuzaki, W., Wollen, J., Yang, S.-K., Hnilo, J. J., Fiorino, M., and Potter, G. L. 2002. NCEP-DOE AMIP-II Reanalysis (R-2). Bull. Am. Meteorol. Soc. 83:1631-1643.
Kawuki, R. S., Tukamuhabwa, P., and Adipala, E. 2004. Soybean rust severity, rate of rust development, and tolerance as influenced by maturity period and season. Crop Prot. 23:447-455.

Kelly, H. Y., Dufault, N. S., Walker, D. R., Isard, S. A., Schneider, R. W., Giesler, L. J., Wright, D. L., Marios, J. J., and Hartman, G. L. 2015. From select agent to an established pathogen, the response to Phakopsora pachyrhizi in North America. Phytopathology 105:905-916.

Krupa, S., Bowersox, V., Claybrooke, R., Barnes, C. W., Szabo, L., Harlin, K., and Kurle, J. 2006. Introduction of Asian soybean rust urediniospores into the Midwestern United States-A case study. Plant Dis. 90: 1254-1259.

Lambert, D. 1997. Zero-inflated Poisson regression, with an application to defects in manufacturing. Techometrics 34:1-14.

Livingstone, D. J., Manallack, D. T., and Tetko, I. V. 1997. Data modelling with neural networks: Advantages and limitations. J. Comput. Aided Mol. Des. 11:135-142.

Maddox, R. L. 1870. On an apparatus for collecting atmospheric particles. Mon. Microsc. J. 3:286-290.

Maddox, R. L. 1871. Observations on the use of the aeroconiscope, or air-dust collecting apparatus. Mon. Microsc. J. 5:45-49.

Matsuki, K., Kuperman, V., and Van Dyke, J. A. 2016. The random forests statistical technique: An examination of its value for the study of reading. Sci. Stud. Read. 20:20-33.

Mehra, L. K., Cowger, C., Gross, K., and Ojiambo, P. S. 2016. Predicting preplanting risk of Stagonospora nodorum blotch in winter wheat using machine learning models. Front. Plant Sci. 7. doi:10.3389/fpls.2016.00390

Melching, J. S., Bromfield, K. R., and Kingsolver, C. H. 1979. Infection, colonization, and uredospore production on Wayne soybean by four cultures of Phakopsora pachyrhizi, the cause of soybean rust. Phytopathology 69:1262-1265.

Miles, M. R., Levy, C., Morel, W., Mueller, T., Steinlage, T., van Rij, N., Frederick, R. D., and Hartman, G. L. 2007. International fungicide efficacy trials for the management of soybean rust. Plant Dis. 91:1450-1458.

Mundt, C. C., Wallace, L. D., Allen, T. W., Hollier, C. A., Kemerait, R. C., and Sikora, E. J. 2013. Initial epidemic area is strongly associated with the yearly extent of soybean rust spread in North America. Biol. Invasions 15:1431-1438.

NOAA. 2006. National Oceanic and Atmospheric Administration. Atmospheric Research Laboratory. NOAA ARL HYSPLIT Model. http://www. arl.noaa.gov/HYSPLIT.php

Olatinwo, R. O., Paz, J. O., Brown, S. L., Kemerait, R. C., Culbreath, A. K., Beasley, J. P., and Hoogenboom, G. 2008. A predictive model for spotted wilt epidemics in peanut based on local weather conditions and the Tomato spotted wilt virus risk. Phytopathology 98:1066-1074.

Olden, J. D., Lawler, J. J., and Poff, N. L. 2008. Machine learning methods without tears: A primer for ecologists. Q. Rev. Biol. 83:171-193.

Oyeyemi, G. M., Ogunjobi, E. O., and Folorunsho, A. I. 2015. On performance of shrinkage methods-A Monte Carlo study. Int. J. Stat. App. 5:72-76.

Pan, Z., Yang, X. B., Pivonia, S., Xue, L., Pasken, R., and Roads, J. 2006. Long-term prediction of soybean rust entry into the continental United States. Plant Dis. 90:840-846.

Paul, P. A., and Munkvold, G. P. 2005. Regression and artificial neural network modeling for the prediction of gray leaf spot of maize. Phytopathology 95:388-396.

R Development Core Team. 2008. R: A Language and Environment for Statistical Computing. R Foundation for Statistical Computing, Vienna, Austria. http://www.r-project.org/

Rapilly, F. 1979. Yellow rust epidemiology. Annu. Rev. Phytopathol. 17:59-73.

Recknagel, F. 2001. Applications of machine learning to ecological modelling. Ecol. Modell. 146:303-310.

Rosso, P. H., and Hansen, E. M. 2003. Predicting Swiss needle cast disease distribution and severity in young Douglas-fir plantations in coastal Oregon. Phytopathology 93:790-798.

Savary, S., and Janeau, J. L. 1986. Rain-induced dispersal of Puccinia arachidis studied by means of a rainfall simulator. Neth. J. Plant Pathol. 92: 163-174.

Schneider, R. W., Hollier, C. A., Whitman, H. K., Palm, M. E., McKemy, J. M., Hernandez, J. R., Levy, L., and Devries-Paterson, R. 2005. First report of soybean rust caused by Phakopsora pachyrhizi in the continental United States. Plant Dis. 89:774

Sikora, E. J., Allen, T. W., Wise, K. A., Bergstrom, G., Bradley, C. A., Bond, J., Brown-Rytlewski, D., Chilvers, M., Damicone, J., DeWolf, E., Dorrance, A., Dufault, N., Esker, P., Faske, T. R., Giesler, L., Goldberg, N., Golod, J., Gomez, I. R. G., Grau, C., Grybauskas, A., Franc, G., Hammerschmidt, R., Hartman, G. L., Henn, A., Hershman, D., Hollier, C., Isakeit, T., Isard, S., Jacobson, B., Jardine, D., Kemerait, B., Koenning, S., Langham, M., Malvick, D., Markell, S., Marois, J. J., Monfort, S., Mueller, D., Mueller, J., Mulroony, R., Newman, M., Osborne, L., Padgett, G. B., Ruden, B. E., Rupe, J., 
Schneider, R., Schwartz, H., Shaner, G., Singh, S., Stromberg, E., Sweets, L., Tenuta, A., Vaiciunas, S., Yang, X. B., Young-Kelly, H., and Zidek, J. 2014. A coordinated effort to manage soybean rust in North America: A success story in soybean disease monitoring. Plant Dis. 98:864-875.

Siroky, D. S. 2009. Navigating random forests and related advances in algorithmic modeling. Stat. Surv. 3:147-163.

Tan, Y., Shan, Z., Shen, M., Yu, Z., Chang, R., Sun, J., Luo, Y., and Xiao, S. 1996. Evaluation of soybean germplasm of china for resistance to soybean rust. Soybean Sci. 16:205-209.

Tschanz, A. T., and Wang, T. C. 1980. Soybean rust development and apparent infection rates at five locations in Taiwan. Prot. Ecol. 2:247-250.
Uddin, W., Serlemitsos, K., and Viji, G. 2003. A temperature and leaf wetness duration-based model for prediction of gray leaf spot of perennial ryegrass turf. Phytopathology 93:336-343.

USDA. 2017. Pest Information Platform for Extension and Education. Published online. http://www.sbrusa.net/

Yang, X. B. 2006. Framework development in plant disease risk assessment and its application. Eur. J. Plant Pathol. 115:25-34.

Yorinori, J. T., Paiva, W. M., Frederick, R. D., Costamilan, L. M., Bertagnolli, P. F., Hartman, G. L., Godoy, C. V., and Nunes, J., Jr. 2005. Epidemics of soybean rust (Phakopsora pachyrhizi) in Brazil and Paraguay from 2001-2003. Plant Dis. 89:675-677. 